\title{
Me chama para conversar que eu gosto: análise de experiência clínico-institucional com a enfermagem de um hospital psiquiátrico
}

\author{
Call me for a conversation and I will enjoy it: analysis \\ of a clinical-institutional experience with the nursing staff \\ of a psychiatric hospital
}

Leonardo Lessa Telles (https://orcid.org/0000-0001-8182-0569) ${ }^{1}$

Sílvia Rodrigues Jardim (https://orcid.org/0000-0003-3942-3345) ${ }^{1}$

Lucia Rotenberg (https://orcid.org/0000-0002-4132-2167) ${ }^{2}$

${ }^{1}$ Instituto de Psiquiatria Universidade Federal do Rio de Janeiro. Av. Venceslau Brás 71/Fundos, Botafogo. 22290-140 Rio de Janeiro RJ Brasil.

leonardolessat@gmail.com ${ }^{2}$ Laboratório de Educação em Ambiente e Saúde, Instituto Oswaldo Cruz, Fiocruz. Rio de Janeiro RJ Brasil.

\begin{abstract}
The teams that work in psychiatric wards are direct heirs of a practice marked by the institutionalizing discourse but need to dialogue with the clinic and care advocated by the Psychiatric Reform. This article aims to analyze how mental health work occurs and what are the relationships between the way of working and the health of nursing workers of a university psychiatric hospital. The theoretical reference used was based on the concepts of activity and self body by Schwartz and the dimension of health established by Canguilhem, understanding that health work is also a work of creation, of production of knowledge and use of their capacities and tacit knowledge. BasedonConversations about Work and Health carried out with the nursing teams of the Institute of Psychiatry of Universidade Federal do Rio de Janeiro (IPUB/UFRJ), we address specific topicsrelated to nursing in mental health. We conclude that there is a very heterogeneous panel of speeches, which express the diversity of ways of thinking and acting in nursing work, so that each worker brings to the scene what they believe to be the best for the patient and it is in the name of that care ethicsthat the most dramatic issues revolvewithin a psychiatric ward.

Key words Nursing, Psychiatric hospital, Mental health, Health and work
\end{abstract}

Resumo As equipes que atuam em enfermarias psiquiátricas são herdeiras diretas de uma prática marcada pelo discurso institucionalizante, mas precisam dialogar com a clínica e o cuidado preconizados pela Reforma Psiquiátrica. O presente artigo tem por objetivo analisar como se dá o trabalho em saúde mental e quais as relações entre o modo de trabalhar e a saúde de trabalhadores de enfermagem de um hospital psiquiátrico universitário. O referencial teórico utilizado teve como base os conceitos de atividade e corpo-si trazidos por Schwartz e a dimensão da saúde estabelecida por Canguilhem, entendendo que o trabalho em saúde é também um trabalho de criação, de produção de saber e de uso de suas capacidades e saberes tácitos. A partir de "Conversas sobre o Trabalho e a Saúde" realizadas com as equipes das enfermarias do Instituto de Psiquiatria da Universidade Federal do Rio de Janeiro (IPUB/ UFRJ), abordamos temáticas especificas da enfermagem em saúde mental. Concluimos que existe um painel bastante heterogêneo de falas, que expressam a diversidade de formas de pensar e agir no trabalho da enfermagem, de modo que cada trabalhador traz à cena aquilo que acredita ser o melhor para o paciente é é nome dessa ética no cuidar que orbitam as questões mais dramáticas dentro de uma enfermaria psiquiátrica.

Palavras-chave Enfermagem, Hospital psiquiátrico, Saúde mental, Saúde do trabalhador 


\section{Introdução}

O trabalho em uma enfermaria psiquiátrica no contexto atual é algo que não está dado. Quando se pensa nas mudanças produzidas pelo movimento da Reforma Psiquiátrica, existem várias possibilidades de narrativa. Neste artigo, pretendemos dar protagonismo às falas dos profissionais de enfermagem que permanecem trabalhando nesta enfermaria e no período histórico que pode ser considerado pós Reforma.

No início da década de 1990, a assistência em saúde mental no Brasil era representada por um modelo que tinha como base os leitos psiquiátricos em hospitais privados, financiados por recursos públicos, quase que exclusivamente. Atualmente, existe a percepção entre profissionais da área de saúde, gestores e opinião pública que essa organização da assistência se traduzia em uma estratégia iatrogênica, de elevados custos sociais e econômicos, com repercussões profundas do ponto de vista coletivo e individual ${ }^{1}$.

Naquele período, o Brasil passou por um amplo processo de discussão sobre as diretrizes para o setor saúde, impulsionadas pelos desdobramentos da redemocratização e ancorados às propostas trazidas pela nova Constituição de 1988, no capítulo que trata das diretrizes para a saúde. Esse processo do setor saúde tem um caminho próprio na área de saúde mental, que tinha o modelo hegemônico centrado no hospital psiquiátrico, já questionado desde o final da década de 1970, quando se constitui o movimento dos Trabalhadores em Saúde Mental, mais tarde transformado no Movimento Nacional da Luta Antimanicomial ${ }^{2}$.

Nesse sentido, conforme expresso por Amarante ${ }^{3}$ :

O que vimos denominando como Luta Antimanicomial ou como Reforma Psiquiátrica tem como princípio básico uma ruptura com essa tradição científica. Em primeiro lugar, por romper com o processo de objetivação da loucura e do louco (inscrevendo a questão homem-natureza ou a questão do normal-patológico em termos éticos, isto é, de relação e não de objetivação). Em segundo lugar, por romper com o processo de patologização dos comportamentos humanos, com base em um pressuposto teleológico ou ontológico da normalidade.

Esse processo encontrou inúmeros obstáculos políticos, sociais e ideológicos, em um primeiro momento representados pelas forças econômicas das velhas resistências oriundas dos setores que têm os seus interesses ameaçados, personificados nos proprietários de clínicas privadas, mas também, e surpreendentemente, pelos segmentos universitários da clínica psiquiátrica que, compartilhando de um percepção biologicista e farmacoterapêutica dos fenômenos mentais, se apoiam em uma dimensão reducionista ao tentar demonstrar que as emoções humanas podem se encerrar em explicações envolvendo neurotransmissores e sinapses que só existem no mundo conceitual.

$\mathrm{Na}$ literatura sobre as mudanças introduzidas pela Reforma Psiquiátrica, muitas são as perspectivas de narrativa nas quais se produziu literatura. A mais recorrente coloca em evidência a dimensão do sujeito louco, ponto de referência a partir do qual se redimensiona toda uma nova maneira de produzir assistência, não mais baseada em um modelo hospitalocêntrico, mas constituída de dispositivos que apontam para a dimensão social, com a construção de novos serviços, espaços de sociabilidade, trocas e produção de subjetividades, substitutivos ao modelo terapêutico tradicional.

Outra perspectiva de narrativa desse processo leva em consideração a dimensão do trabalhador em saúde mental. O campo de trabalho constituído pela lógica dessa rede substitutiva de atenção ganha destaque, a partir da reflexão sobre conflitos, ambiguidades e contradições que se expressam nas relações no cotidiano de trabalho, considerando as manifestações que surgem das contradições entre os ideais antimanicomiais e aqueles herdados da psiquiatria clássica. Nesta perspectiva estão os estudos realizados em Centros de Atenção Psicossocial ${ }^{4}$ (CAPS) e em Serviço Residencial Terapêutico 5 .

Porém, a discussão sobre os profissionais que mantiveram sua atuação nos dispositivos de internação psiquiátrica é exígua. Pode-se dizer que estes trabalhadores são herdeiros diretos de uma prática assistencial marcada pelo discurso institucionalizante, mas que, por outro lado, se veem obrigados a dialogar com os representantes dessa nova maneira de pensar a clínica.

A relevância desta questão se deve à constatação de que a literatura sobre o trabalho em enfermagem conta com relativamente poucos estudos voltados para a saúde mental. De fato, a maior parte do material bibliográfico produzido no Brasil tem como protagonismo o contexto de hospitais gerais e de maternidades ${ }^{6-8}$. Os poucos trabalhos que tratam da enfermagem em saúde mental focam as questões da Reforma Psiquiátrica $^{9,10}$, fora do ambiente hospitalar ${ }^{5}$. Alguns estudos realizados em hospitais psiquiátricos ${ }^{10}$ não abordam diretamente as questões da assistência 
sob a influência da Reforma Psiquiátrica, atendose às questões das agressões e contenções ${ }^{11}$, tão prevalentes no trabalho em saúde mental. Já o estudo conduzido por Rodrigues et al. ${ }^{12}$ descreve a trajetória de um hospital psiquiátrico de 1994 a 1998, considerando as dificuldades e conflitos enfrentados na busca por uma assistência compatível com os preceitos da Reforma Psiquiátrica.

No contexto dessa discussão, cabe questionar: como se dá o trabalho da enfermagem em uma enfermaria psiquiátrica em tempos de Reforma? Como as equipes de enfermagem lidam com as diferentes formas de pensar a clínica e o cuidado em saúde mental? Como os trabalhadores da enfermagem de um hospital psiquiátrico vivenciam a transição entre o modelo hospitalocêntrico e aquele traduzido pelos preceitos da Reforma? Buscando contribuir para a compreensão destas questões, o presente estudo tem por objetivo analisar como se dá o trabalho em saúde mental no contexto de um hospital psiquiátrico universitário, na perspectiva das equipes de enfermagem.

Para lidar com estas questões, optamos por utilizar um referencial teórico que valoriza o conhecimento e a experiência dos trabalhadores, os aspectos gerais e as especificidades da atividade, suas normas e variabilidades, a exigência de diálogo entre as várias disciplinas e o constante questionamento a respeito de seus saberes ${ }^{13}$, como descrito no item que se segue.

\section{Lupa teórica para leitura do artigo}

Quando levantamos essas questões sobre o trabalho da enfermagem em uma enfermaria psiquiátrica na contemporaneidade, o desafio que se apresenta é sob quais perspectivas teóricas e metodológicas essas questões poderiam ser avaliadas. Acreditamos que ao se abordar o trabalho no micronível, como sob uma lupa, ou seja, a partir do que se denomina a atividade de trabalho, esse campo da experiência humana parece especialmente propício a responder interrogações que envolvam singularidades no tratamento de situações de vida, assim buscamos uma abordagem teórica que favorecesse essa visualização do micro.

O referencial teórico utilizado neste artigo leva em consideração a dimensão de saúde estabelecida por Canguilhem ${ }^{14}$, segundo o qual "está ligada tanto ao meio em que vivemos, quanto à capacidade que temos e desenvolvemos, individual e coletivamente, para transformá-lo segundo nossos anseios" 15 . Segundo as autoras:

Trata-se de uma noção associada à capacidade de produção de novas formas de vida (e não mera ausência de doença) e que ressalta a existência de uma dimensão do corpo só acessível ao próprio sujeito, sinalizando a necessidade de constante diálogo com aquele que vivencia a experiência do seu corpo, da sua dor e do seu adoecimento para compreendê-lo.

Ao transpor essa dimensão de saúde para o ambiente de trabalho, poderíamos pensá-la como uma tentativa de equilíbrio mais ou menos aceitável entre suas próprias normas, provenientes de sua própria história, com a do coletivo social, que é mais amplo, ou da vida da nação ou do universo social, econômico, humano. Os trabalhadores descobrem a melhor maneira de atuar, inventando um modo de trabalhar, mais afim a seus valores. Mas a doença, ou a patologia, é também o risco permanente de não poder manter esse equilíbrio, o risco de que esse debate de normas se desenvolva em desvantagem permanente.

Desta forma, é possível pensar que o normativo em determinadas situações pode se tornar patológico em outras, de tal maneira que cabe ao indivíduo avaliar essa sutileza de transformação, pois é ele próprio o sujeito que arca com as consequências dessas mudanças e também aquele que é capaz de renormatizar as suas condições de vida, garantindo assim sua saúde ${ }^{14}$.

O conceito estabelecido por Canguilhem quanto à perspectiva renormatizadora impressa à dimensão da saúde é retomado por Schwartz, no estabelecimento das bases que fundamentam a perspectiva ergológica, na medida em que cada pessoa vai lidar com as "lacunas" ou as deficiências a seu modo, pois ela não pode fazê-lo de uma maneira padronizada. Estas lacunas estão relacionadas com o que a ergonomia de origem francesa refere como a distância entre o trabalho prescrito e real ${ }^{13}$. Para os ergonomistas de língua francesa, o trabalho prescrito configura as regras e os modos de execução do trabalho que é concebido e codificado por uma instância superior e, portanto, caracteriza-se por não ser definido pelo trabalhador. Entretanto, uma vez que não existe a possibilidade de descrevê-lo totalmente, o trabalho executado é diferente do prescrito e este recebe o nome de trabalho real ${ }^{16}$. Assim, o trabalho real refere-se àquilo realmente colocado em ação pelo trabalhador, o que realmente acontece em seu local de trabalho.

A existência dessas lacunas fica ainda mais evidenciada na medida em que o trabalho real se distancia do prescrito e parecem ser mais facilmente superadas pela categoria de trabalhadores para a qual damos destaque nesse artigo quando a prescrição não se torna um empecilho ao 
desempenho do trabalho real. Conforme Duraffourg et al. ${ }^{17}$, o trabalho prescrito tende a se dissolver, ou seja, pode estar:

Formalizado nos livros sobre a organização, ele pode ser afixado num mural, ser objeto de esquemas, modelos, razões. Ele é registrável, é visivel, pode ser verbalizado. Por outro lado, tudo o que éda ordem do real é dificilmente visto e expresso. Quantos trabalhadores dizem: 'eu estou acostumado', e não conseguem verbalizar sua maneira de fazer!

Em razão disso, a Ergologia privilegia o conceito de "normas antecedentes", que engloba o conceito ergonômico de trabalho prescrito ${ }^{18}$. Segundo Vieira-Júnior e Santos ${ }^{19}$ o conceito de "normas antecedentes" [...] é mais abrangente que o seu precursor [trabalho prescrito], por incorporar várias dimensões presentes nas situações de trabalho, como: as aquisições de inteligência do trabalhador, as experiências coletivas, o saberfazer, as construções históricas analisadas como patrimônio cultural e científico, a dimensão dos valores, que transcende a questão monetária e se posiciona na esfera do político, dos debates e dos conflitos que findam por compor o caráter híbrido desse conceito.

O trabalho nunca é pura execução, principalmente porque o meio é sempre infiel, uma vez que ele jamais se repete exatamente de um dia para o outro, ou de uma situação para a outra, sendo necessário fazer uso de suas próprias capacidades, de seus próprios recursos e de suas próprias escolhas para gerir essa infidelidade. Isso é o que Schwartz chama de "vazio de normas", porque aí as normas antecedentes são insuficientes, visto que não há somente execução ${ }^{13}$. Essa é a razão pela qual se poderia dizer que não há execução, mas uso. Uso de si, mas com essa dualidade às vezes simples, mas também complexa, que é o uso de si "por si" e "pelos outros". E é precisamente porque há ao mesmo tempo esses dois momentos, ou essas duas polaridades do uso, que todo trabalho é problemático e frágil, comportando um drama.

O uso de si por si refere-se ao posicionamento que cada trabalhador toma diante das normas com as quais se depara, confrontando-as e alterando-as, fazendo escolhas e arriscando-se, enquanto o uso de si pelos outros remete a um conjunto de estatutos diversos, uma vez que jamais se trabalha totalmente sozinho. Os "outros" podem ser os colegas de trabalho ou ainda podem estar fora da proximidade imediata. Tudo isso está presente na intimidade das escolhas que o trabalhador faz sobre esse ou aquele procedimento, fazendo do trabalho uma realidade profundamente coletiva e profundamente individual, visto que é profundamente singular.

É nesse sentido que Schwartz e Durrive ${ }^{13}$ afirmam que em toda atividade de trabalho há sempre "uso de si", de tal modo que o trabalhador e todo o seu ser é convocado no exercício de suas atividades, e não apenas partes do seu corpo. Mesmo no mais taylorista dos cenários a atividade produz uma dialética entre a heterodeterminação (uso de si por outro) e a singularização (uso de si por si), não sendo possível entender o trabalhador como um simples executor passível das normas antecedentes.

Para falar sobre o trabalhador e as questões por ele engendradas, a Ergologia não utiliza o conceito de subjetividade, mas sim de "corpo-si", considerado o árbitro mais intimo da atividade e não um sujeito delimitado, definido, mas uma entidade enigmática que resiste às tentativas de ser objetivado assim, o "corpo-si" é o árbitro e gestor dessas variabilidades que o impulsionam a escolher entre trabalhar "por si" ou "pelos outros", gerindo, assim, seu trabalho. Conforme Schwartz e Durrive ${ }^{13}$, essa gestão é atravessada por economias do corpo, por sinalizações sensoriais e visuais, por um tipo de inteligência que passa pelo muscular, pelo neurofisiológico, mas que em seguida passa pela inconsciência do próprio corpo e pelo histórico.

O trabalhador é constantemente confrontado com variabilidades na realização de suas atividades, sendo necessária a realização constante de escolhas relacionadas à execução de suas atividades de trabalho. Em decorrência, a entidade que arbitra e decide não é inteiramente biológica, nem inteiramente consciente ou cultural, e é por isso que a ideia de "corpo-si" é posta pelos autores como preferível às noções de sujeito ou de subjetividade. Assim tem-se a vantagem de não veicular [...] certo número de possiveis malentendidos ou de evidências que criam obstáculos", uma vez que todo conceito carrega consigo uma história, apostas e valores ${ }^{13}$.

As perguntas que cabem fazer são: como suprir essa lacuna entre o trabalho prescrito e o real? Que tipos de invenções são necessárias fazer para poder trabalhar? As respostas a essas perguntas envolvem a consideração de outras questões, inclusive as que abordam o meio no qual os trabalhadores estão inseridos. É sobre o meio e a sua infidelidade que Schwartz e Durrive ${ }^{13}$ esclarecem que como o meio jamais se repete, o trabalhador precisa fazer suas próprias escolhas para gerir essa infidelidade, gerindo essa infidelidade do meio através do "uso de si". 
Os conceitos da ergologia já foram utilizados no contexto da atividade da enfermagem ${ }^{20}$. Oliveira e Alessi ${ }^{21}$, ao falarem sobre analisarem o trabalho da enfermagem em saúde mental, se detiveram sobre as possíveis contradições e os desafios envolvidos no processo de trabalho da enfermagem em saúde mental no contexto da Reforma Psiquiátrica. Silva e Azevedo ${ }^{5}$ valorizaram a percepção dos trabalhadores de enfermagem sobre a assistência em saúde mental em um hospital universitário, concluindo que os trabalhadores apresentaram dificuldades nas atividades de cuidado aos pacientes em sofrimento, tendo sido as limitações mais valorizadas do que as potencialidades. Já Muniz et al. ${ }^{22}$ apontam para a necessidade de se encontrar um caminho para a equipe de enfermagem, no contexto da atenção psicossocial, para que se supere a assistência restrita à vigília, às contenções e às injeções, procurando a contextualização do cuidado com a lógica da Reforma Psiquiátrica.

Uma revisão bibliográfica dos estudos sobre a subjetividade no trabalho em enfermagem a partir da perspectiva ergológica revela a defasagem entre a organização prescrita e a organização real do trabalho, em que as intercorrências dão margem à liberdade criadora. Assim, evidenciouse que os enfermeiros vivenciam momentos de articulação de suas ações e interações, revelando uma tendência em superar a fragmentação ${ }^{23}$.

Desvendar a dinâmica das situações entre trabalho e a sua saúde, com particular enfoque à saúde mental implica um empenho dedicado de aproximação e teorização, capaz de ampliar a interpretação de um quadro aparentemente dado e imutável, que condiciona a formulação de alternativas organizacionais, e cujas repercussões certamente não se restringem somente aos locais de trabalho.

Com o objetivo de dar materialidade a essas questões, será analisado neste artigo o material empírico obtido a partir de atividade de caráter clínico-institucional, denominada Conversas sobre o Trabalho e a Saúde (doravante, denominadas Conversas), nas quais a equipe do Projeto de Atenção à Saúde Mental do Trabalhador da Universidade Federal do Rio de Janeiro (PRASMET - UFRJ) tem ido até as enfermarias masculina e feminina do IPUB, para criar um momento de diálogo com os trabalhadores da enfermagem, e que envolvem discussões e diálogos sobre o trabalho nas enfermarias e sua relação com a saúde. O fluxo de atendimento e as atividades clínico-institucionais realizadas pela equipe do PRASMET foram descritos em outro artigo ${ }^{23}$.

\section{Métodos}

Este artigo, de caráter descritivo-qualitativo, integra a pesquisa intitulada "Trabalho na universidade e saúde mental: o verso e o reverso do adoecimento mental nos profissionais de enfermagem psiquiátrica universitária", aprovada pelos Comitês de Ética da Escola Nacional de Saúde Pública Sergio Arouca (ENSP/Fiocruz) e do Instituto de Psiquiatria da Universidade Federal do Rio de Janeiro (IPUB/UFRJ).

O grupo de pesquisa que desenvolve suas atividades em torno da categoria de trabalhadores da enfermagem está incluído no PRASMET - UFRJ e os resultados apresentados no presente artigo se baseiam no acervo de gravações colhidas nas Conversas sobre o Trabalho e a Saúde. Foram realizadas 11 Conversas com as equipes que trabalham nas enfermarias masculina e feminina do IPUB, nos plantões diurno e noturno e todos os 40 participantes foram consultados quanto à anuência ou não do uso das gravações realizadas durante estas atividades (Termo de Consentimento Livre e Esclarecido).

O diálogo com a categoria de trabalhadores foi realizado a partir de um roteiro flexível, que buscava abordar basicamente quatro eixos temáticos: (1) a trajetória profissional até chegar ao trabalho no IPUB, (2) a rotina de trabalho da enfermagem no Instituto, (3) os modos de trabalhar e de lidar com o imprevisto e (4) as questões que precisam ser modificadas no ambiente de trabalho. As gravações das Conversas foram transcritas integral e literalmente.

A análise desse material foi feita pela leitura das transcrições e a seleção de trechos da narrativa estabelecida em um primeiro momento com os trabalhadores, através de categorizações temáticas. Durante a etapa da exploração do material, seguiu-se com a construção das categorias que, orientada pelas questões do estudo, permitiu organizar o conteúdo exposto na fala do grupo selecionado, com o objetivo de compreender e explorar o material a partir dos temas identificados.

\section{Resultados e discussão}

Durante a realização das Conversas estava muito evidente o sentimento conflituoso que envolve o trabalho da enfermagem nesse contexto. A questão central que permeou o estudo diz respeito aos conflitos que invadem as relações e situações de trabalho em um hospital psiquiátrico no período pós-reforma. Em torno desse eixo central or- 
bitam aspectos temáticos os quais discutiremos adiante de maneira mais detalhada.

Foi possível identificar quatro grupos temáticos de discussão, que envolvem as percepções das questões de trabalho influenciadas pela perspectiva da Reforma Psiquiátrica, as estratégias de contenção e dimensão de cuidado que esse procedimento produz, a inclusão da agressão física como algo que parece estar prescrito na rotina de trabalho da enfermagem psiquiátrica e as questões que surgem a partir da interface de trabalho entre a enfermagem e outras categorias profissionais, médicas ou não. No presente artigo, nos detemos no primeiro tópico, sendo as demais questões discutidas em futura publicação.

A divisão por tópicos foi um exercício de escrita, que se por um lado tende a facilitar a compreensão dos núcleos temáticos mais recorrentes das falas dos trabalhadores, por outro incorre na limitação de reduzir a atmosfera de ebulição contagiante que marcou o clima dos encontros.

Nas falas oriundas das Conversas, observamos que o dispositivo físico do leito psiquiátrico passou a representar o espaço em torno do qual a discussão sobre o papel e as limitações de atuação dos profissionais de enfermagem vêm ganhando cada dia mais força. Parece se tornar palco para o diálogo entre correntes ideológicas polarizadas, que no IPUB ganharam a denominação de “Capsistas” e, por força de antagonização, as “não Capsistas". Historicamente, isso pode ser explicado por um modelo de formação mais tradicional que teve o manicômio como cenário de ensino e aprendizagem. Este contraste se expressa, por exemplo, na fala de uma das enfermeiras que participaram das Conversas:

- A minha história não é dentro do hospital psiquiátrico, acho que eu também preciso situar vocês. Eu fiz residência, eu trabalhei em CAPS anos e aí eu passo pra esse concurso, me deparo num primeiro momento com a alegria de ser concursada, mas com a tristeza de estar nessa enfermaria, um lugar que é duro, condições inóspitas, um lugar muito difícil porque já lida com o sofrimento, num lugar que não te dá a menor estrutura. É hierárquico demais, não tem uma horizontalidade, entre as relações, a relação é sempre num nível hierárquico, seja entre a enfermagem e a medicina, enfermagem e direção, não sei o que, então, é muito difícil, garantir autonomia, poder trabalhar com o usuário. Muito difícil, é adoecedor, $a$ gente também tem um limite, a gente faz atividades, tenta fazer alguma coisa diferente, mas a gente tem um limite institucional (grifo nosso).

Observamos nessa fala a crítica à cultura institucional que prima por relações de natureza hierarquizada, muito diferente do modo como vivenciou na sua formação. Desta forma, percebe que ao não conseguir trabalhar de acordo com seus anseios e expectativas, o indivíduo adoece. Quando se pensa que "todo homem quer ser sujeito de suas normas"14, o que está em debate é a possibilidade do indivíduo em fazer algo e, ao mesmo tempo, construir a si mesmo, mantendo sua individualidade, em consonância com seus valores e estabelecendo sua maneira própria de se confrontar com as normas. A impossibilidade disso acontecer é algo "adoecedor", conforme dito acima, estando, portanto, o adoecimento ligado à impossibilidade de renormatizar o meio, ou ainda, de equilibrar as demandas do meio e todo o conteúdo de normas existentes com o conjunto de expectativas, valores pessoais e individualidades.

Em nossas Conversas pudemos observar que apenas os profissionais de enfermagem com formação mais recente tinham vivência clínica nos dispositivos de assistência extra-hospitalar, enquanto os trabalhadores com formação mais antiga ainda não existia uma padronização do ensino dos conteúdos referentes à Saúde Mental no contexto da Reforma ${ }^{24}$. A base da atividade desses profissionais é empírica e foi assim descrita pela mais antiga técnica de enfermagem do grupo:

- Quando eu cheguei aqui (há mais de 30 anos), nós éramos dois funcionários, dois técnicos que trabalhávamos, não tínhamos enfermeira... Aqui eram 50 mulheres, do outro lado 40 homens $e$, assim, se um de nós adoecesse ou acontecesse qualquer coisa, por qualquer motivo, ficava um. E nós funcionávamos da seguinte maneira: éramos porteira, quando necessário faxineira, dávamos medicação, cuidávamos do paciente como um todo $e$ acho que isso é muito desgastante. Gostei muito das mudanças que aconteceram, de Cristina Loyola para frente, porque foi com ela que vieram algumas mudanças muito boas e outras péssimas, como por exemplo pacientes juntos, enfermaria mista. [...] Mas eu também acho que a psiquiatria mudou muito, tanto para nós funcionários, como para os pacientes. Nós, funcionários do IPUB, como eu já falei com a $V$. que é nova, que trabalha no CAPS, eu acho que somos considerados o capeta com tridente, que cutuca.

\section{- Por quê?}

- Porque nós somos vistos como os repressores, nós somos vistos como aqueles profissionais que quando ainda não se sabe, a gente faz a contenção, a gente medica e eu não tenho vivência de CAPS, mas que parece que isso lá não acontece. Mesmo porque não são pacientes que estão na fase aguda, estão muito light, mas eu gostaria que mudasse 
também, que tivesse mais profissionais envolvidos, os multiprofissionais. Que agora tem o lado bom, tem o lado péssimo, porque essa convivência às vezes é muito boa, às vezes não.

A dificuldade para sintetizar uma série de demandas que emanam de uma permanência de 24 horas ao lado do paciente, a impossibilidade de parcerias, as dificuldades de diálogo com outros profissionais do hospital e o desafio em lidar com uma pluralidade de teorias e práticas são questões importantes a serem apontadas na prática diária desses profissionais ${ }^{21}$.

É importante dar destaque ao fato de que em nossas Conversas existe um painel bastante heterogêneo de falas, que expressam a diversidade de formas de pensar e agir no trabalho da enfermagem, mas há algo de sutil que os aproxima e que trata justamente dessa ambiciosa tentativa de conciliar o fazer com a conservação da singularidade. É desse exercício homeostático que nasce a riqueza das invenções com as quais nos deparamos em nossa atividade, mas também é desse lugar que brotam as situações de conflito, na medida em que não é totalmente possível conciliar todos os valores pessoais.

Há, portanto, uma pluralidade de normas (muitas vezes paradoxais), sendo os trabalhadores convocados a fazer escolhas de maneira permanente e estando em contato diário com a pluralidade de modos de pensar e de fazer, vivenciando a constante tensão de se confrontar com elas ${ }^{18}$.

Ao se lançar um olhar mais histórico sobre essa questão, é preciso destacar que a Escola de Enfermagem Anna Nery da UFRJ, fundada em 1923, no Rio de Janeiro, é considerada a primeira escola de enfermagem "moderna" do Brasil, pela historiografia oficial. No entanto, até 1949 não há em seu currículo nenhuma matéria relacionada às doenças mentais, quando passou a desenvolver estágio no Centro Psiquiátrico Nacional - Engenho de Dentro. Com a necessidade de inclusão dos referenciais da Reforma Psiquiátrica na formação da enfermagem, o que se observa, do ponto de vista prático, é uma certa indefinição dos profissionais de enfermagem psiquiátrica sobre o seu papel nessa assistência, produzindo, muitas vezes, uma "fuga" para o desempenho de atividades burocrático-administrativas, que passa a constituir como uma identidade possível para esses profissionais que vivenciam uma prática marcada pela indefinição de seu papel. Miranda et al. ${ }^{25}$ chamam a atenção para a dificuldade vivida pelo(a) enfermeiro(a) psiquiátrico, ao abordar o cuidado de enfermagem psiquiátrica, fundamentado na discussão sobre novas formas de cuidar e de ensinar a cuidar em enfermagem psiquiátrica.
Com a chegada de profissionais de enfermagem formados no contexto da Reforma Psiquiátrica, a partir da experiência em dispositivos como os Centros de Atenção Psicossocial (CAPS), cria-se um contexto de espaço de trabalho com maior possibilidade de troca social e se reestabelece uma nova mentalidade de cuidado, diferente daquela baseada em atividades que simplificam o cuidado da enfermagem psiquiátrica a um "pastoreio gentil". Esse processo ocorre com desconfortos nas relações cotidianas, conforme podemos notar nas falas dos profissionais escutados nas Conversas. Diferente dos profissionais mais antigos da instituição, que em sua maioria chegaram à especialidade por uma necessidade de rápida absorção no mercado, os profissionais de enfermagem recém-concursados passaram por treinamento técnico qualificado, atuam em uma área que escolheram e exigem condições de trabalho de forma adequada às suas disponibilidades internas e clínico-institucionais, independente de serem auxiliares e técnicos de enfermagem ou enfermeiros.

Quando nos deparamos com a enfermeira que mais recentemente foi admitida em concurso e com histórico de qualificação em Saúde Mental, encontramos o seguinte relato:

- (Eu) passei tem 6 meses. Ouvindo os antigos falarem, acho que é uma outra trajetória! Acho que aqui representa várias trajetórias diferentes, de vários momentos da psiquiatria, da política, talvez cada um tenha uma experiência diferente, de um lugar diferente da experiência, acho que sou a mais recente.

Além disso, no que se refere à concepção de objeto que permeia o processo de trabalho da enfermagem em saúde mental, apesar de uma expectativa inicial de que o discurso dos(as) enfermeiros(as) pudesse estar orientado segundo a lógica predominantemente manicomial, uma vez que estávamos dentro de um hospital psiquiátrico concebido em um modelo clássico organicista, o que vimos em nossas Conversas apontava ambivalência em relação ao discurso e às práticas de cuidado desses profissionais. Mesmos os profissionais formados pela empírica escola do IPUB, conforme o relato acima, já foram tocados pelas novas maneiras de olhar e conceber as práticas de atenção aos pacientes.

Por outro lado, existe uma tendência à manutenção de práticas tradicionais - que incluem tomar conta da expressão da sexualidade dos pacientes, das medicações prescritas pelos médicos, das roupas, da lavanderia e controle principalmente medicamentoso dos pacientes em crise -, embora o discurso já aponte para atividades de 
relacionamento interpessoal e trabalho interdisciplinar, demarcando ainda que os trabalhadores da enfermagem, imersos em contradições e potencialidades.

Porém, o que observamos nas nossas Conversas é um processo marcado por tendências a rever constantemente os modos de fazer em função do que é melhor para o paciente. Conforme dito pela mesma técnica de enfermagem com mais tempo de trabalho na instituição:

- Porque a gente precisa que as coisas mudem, que as coisas evoluam! Por que ter que fazer um procedimento desse? Porque, eu acho que a gente fazia, quando começou, porque não tínhamos noção, há trinta e poucos anos atrás nós não tínhamos conhecimento. A partir do momento que a gente vai tendo mais conhecimento, vai tendo mais saber, você fala assim: não, vamos melhorar isso aqui!

- E ai foi o que foi acontecendo, eu fui começando a dizer não, outro aqui, ela aqui, outro ali e nós fomos começando a dizer não, então vamos reunir todo mundo e vamos ver como é que vai ser feito. Do nosso jeito (grifo nosso).

Em artigo que trata da relação entre enfermeiros e médicos em um hospital escola, Oliveira e Alessi ${ }^{21}$ observam que embora reconheçam a limitação do modelo médico psiquiátrico na abordagem do sujeito com transtornos mentais, os trabalhadores da enfermagem ainda se ocupam, rotineiramente, da 'doença mental' ao controlar o comportamento dos usuários e apesar de criticar o tratamento ofertado pela instituição - pautado pelo modelo organicista - não se percebem como agentes de transformação dessa realidade. Porém, o que vimos em nossa atividade é que essa maneira de fazer encontra poros importantes para construção de novas formas de cuidado, até mesmo nos profissionais cujas atividades remontam aos tempos mais fundamentais da instituição.

\section{Considerações finais}

Observamos aspectos específicos à categoria da enfermagem que se dedica ao trabalho em saúde mental em enfermarias psiquiátricas, que refletem os dilemas colocados em sua prática diária e toda a engenharia de estratégias da qual lançam mão para poder continuar trabalhando, desveladas a partir do referencial teórico utilizado nas análises.

Um aspecto presente nas Conversas, e que permeia algumas falas aqui apresentadas são as situações de trabalho em que os trabalhadores primam por buscar o que lhes parece melhor para o paciente como, por exemplo, promover o contato com a família, que pode significar um ansiolítico a menos, usar expressão "não medica, não" ou, mesmo, conversar com o paciente sobre a própria contenção.

Ao refletirmos sobre as necessidades e possibilidades específicas do trabalho de enfermagem em equipe de saúde mental, na perspectiva de ampliação do objeto de intervenção proposto pela Reforma Psiquiátrica, o trabalho nessa área ganha novos contornos, como, por exemplo, apresenta-se a necessidade de que a esse objeto redesenhado, corresponda novos instrumentos e, nesse sentido, aconteçam algumas modificações nas práticas terapêuticas, como a incorporação de trabalhadores "atípicos" na equipe, como artistas plásticos, professores de educação física, dentre outros; além do que a finalidade do trabalho proposto nessa concepção não admite mais a noção de "cura", mas de reabilitação, reinserção social. Os instrumentos para esse fim, portanto, não podem continuar sendo os meios físicos $\mathrm{e}$ químicos coercitivos, mas outros que proporcionem a escuta e a valorização do sujeito-cidadão que sofre mentalmente ${ }^{4}$.

Essas modificações no processo de trabalho de saúde mental levam-nos a considerar a necessidade de mudanças na divisão desse trabalho coletivo ${ }^{26}$. Esse trabalho interdisciplinar pressupõe a coexistência de ações técnicas específica a cada categoria profissional e a execução de algumas ações comuns com tendência à construção de uma linguagem de trabalho comum com menor horizontalização das relações de poder. Entretanto, essa aproximação das áreas profissionais no plano técnico do trabalho - desempenho de atividades com uma diluição gradativa das peculiaridades - é acompanhada de tensão no aspecto dos valores dos diferentes trabalhos, uma vez que as relações hierárquicas são mantidas e reproduzidas, principalmente entre os profissionais médicos e não-médicos, referentes a salário e ao fato de o médico ser o responsável pela atenção ao usuário ${ }^{27}$.

Quanto à percepção das ambivalências em relação ao discurso e às práticas de cuidado dos profissionais, é necessário estabelecer o diálogo entre os mais diversos setores do Instituto, com objetivo de fazer valer o protagonismo da enfermagem em suas mais diversas formas de pensar e cuidar nessa modalidade tão delicada da saúde.

Ao contrário do que se poderia pensar, o que se observou em nossas Conversas não foi um palco de vaidades em que cada trabalhador traz à cena aquilo que pensa ser o melhor para si, mas 
o que acredita ser o melhor para o paciente e é em nome dessa ética no cuidar que orbitam as questões mais dramáticas da enfermagem dentro de uma enfermaria psiquiátrica.

\section{Colaboradores}

LL Telles, SR Jardim e L Rotenberg participaram da construção científica do artigo, considerando as etapas de atividades de campo, redação, leitura e revisão.

\section{Referências}

1. Kilsztajn S, Lopes ES, Lima LZ, Rocha PAF, Carmo MSNC. Leitos hospitalares e reforma psiquiátrica no Brasil. Cad Saude Publica 2008; 24(10):2354-2362,

2. Hirdes A. A reforma psiquiátrica no Brasil: uma (re) visão. Cien Saude Colet 2009; 14(1):297-305.

3. Amarante P. Manicômio e loucura no final do século e do milênio. In: Fernandes MIA, Scarcelli I, Costa ES, organizadores. Fim de século: ainda manicômios? São Paulo: Universidade de São Paulo; 1999.

4. Zerbetto SE, Efigênio EB, Santos NLN, Martins SC. O trabalho em um Centro de Atenção Psicossocial: dificuldades e facilidades da equipe de enfermagem. Rev. Eletr. Enf. 2011; 13(1):99-109.

5. Silva DS, Azevedo DM. A reforma psiquiátrica na visão de quem cuida: percepções de profissionais do serviço residencial terapêutico. Esc. Anna Nery 2011; 15(3):587-594.

6. Shimizu HE, Ciampone MHT. Sofrimento e prazer no trabalho vivenciado pelas enfermeiras que trabalham em unidades de terapia intensiva em um hospital escola. Rev. Esc. Enf. USP 1999; 33(1):95-106.

7. Elias MA, Navarro VL. A relação entre o trabalho, a saúde e as condições de vida: negatividade e positividade no trabalho das profissionais de enfermagem de um hospital escola. Rev. Latino-am. Enfermagem 2006; 14(4):517-525.

8. Santos JLG, Pestana AL, Guerrero P, Meirelles BSH, Erdmann AL. Práticas de enfermeiros na gerência do cuidado em enfermagem e saúde: revisão integrativa. Rev. Bras. Enferm. 2013; 66(2):257-263.

9. Fernandes JD, Sadigursky D, Silva RMO, Amorim AB, Teixeira GAS, Araújo MCF. Ensino da enfermagem psiquiátrica/saúde mental: sua interface com a Reforma Psiquiátrica e diretrizes curriculares nacionais. Rev. Esc. Enf. USP 2009; 43(4):962-968.

10. Lucchese R. A enfermagem psiquiátrica e saúde mental: a necessária constituição de competências na formação e na prática do enfermeiro. Rev. Esc. Enf. USP 2007; 9(3):883-885. 
11. Carvalho MB, Felli VEA. O trabalho de enfermagem psiquiátrica e os problemas de saúde dos trabalhadores. Rev. Latino-am. Enfermagem 2006; 14(1):61-69.

12. Rodrigues AAP, Xavier ML, Figueiredo MAG, Almeida Filho AJ, Peres MAA. Influências da Reforma Psiquiátrica no cuidado de enfermagem na Casa de Saúde Esperança em Juiz de Fora, Minas Gerais, Brasil (19941998). Texto Contexto Enferm. 2016; 25(2):e1450014.

13. Schwartz Y, Durrive L. Trabalho \& Ergologia: Conversas sobre a atividade humana. $2^{\text {a }}$ ed. Niterói; Ed. UFF: 2010.

14. Canguilhem G. O normal e o patológico. $6^{\mathrm{a}}$ ed. Rio de Janeiro: Forense Universitária; 2009.

15. Brito JC, Neves MY, Oliveira SS, Rotenberg L. Saúde, subjetividade e trabalho: o enfoque clínico de gênero. Rev. Bras. Saúde Ocup. 2012; 37(126):316-329

16. Dejours C. Por um novo conceito de saúde. Revista Brasileira de Saúde Ocupacional 1986; 14(54):7-11.

17. Duraffourg J, Duc M, Durrive L. O trabalho e o ponto de vista da atividade. In: Schwarz Y, Derrive L, organizadores. Trabalho \& Ergologia: Conversas sobre a atividade humana. 2a ed. Niterói: Ed. UFF; 2010. p. 47-87.

18. Telles AL, Alvarez D. Interfaces ergonomia-ergologia: uma discussão sobre trabalho prescrito e normas antecedentes. In: Figueiredo M, Athayde M, Brito J, Alvarez D, organizadores. Labirintos do trabalho: interrogação e olhares sobre o trabalho vivo. Rio de Janeiro: DP\&A; 2004. p. 63-90.

19. Vieira-Júnior PR, Santos EH. A gênese da perspectiva ergológica: cenário de construção e conceitos derivados. Trabalho \& Educação 2012; 21(1):83-100.

20. Santos TM, Camponogara S. Um olhar sobre o trabalho de enfermagem e a ergologia. Trab. Educ. Saúde 2014; 12(1):149-163.

21. Oliveira AGB, Alessi NP. O trabalho de enfermagem em saúde mental: contradições e potencialidades atuais. Rev Latino-Am Enfermagem 2003; 11(3):333-340.
22. Muniz MP, Tavares CMM, Abrahão AL, Souza AC. A assistência em enfermagem em tempos de reforma psiquiátrica. Revista Portuguesa de Saúde Mental 2015; 13:61-65.

23. Telles LL, Klein VF, Oliveira VG, Ribeiro IC, Gomes V, Couto EW, Cavalcanti N, Oliveira CA, Lemos RR, Amendoeira MC, Castro GH, Jardim S, Rotenberg L. O Projeto de Atenção à Saúde Mental dos Trabalhadores da Universidade Federal do Rio de Janeiro - PRASMET: 20 anos. [no prelo].

24. Vargas D, Maciel MED, Bittencourt MN, Lenate JS, Pereira CF. O ensino da enfermagem psiquiátrica e saúde mental no Brasil: análise curricular da graduação. Texto Contexto Enferm. 2018; 27(2):e2610016.

25. Miranda CML, Rocha RM, Sobral VRS. O ensino, a pesquisa e a assistência de Enfermagem psiquiátrica. Revista de Enfermagem UERJ 1999; 7(2):189-192.

26. Paes MR, Borba LO, Brusamarello T, Guimarães AN, Maftum MA. Contenção Física em Hospital Psiquiátrico e a Prática da Enfermagem. Rev. Enferm. UERJ 2009; 17(4):479-484.

27. Peduzzi M. Equipe multiprofissional de saúde: a interface entre trabalho e interação [tese]. Campinas: Unicamp; 1998.

Artigo apresentado em 07/04/2019

Aprovado em 20/08/2019

Versão final apresentada em 03/10/2019 